\title{
ENHANCING COPPER AND LEAD BIOACCUMULATION IN RAPESEED BY ADDING HEMP SHIVES AS SOIL NATURAL AMENDMENTS
}

\author{
Corneliu TANASE ${ }^{a}$, Irina VOLF ${ }^{b}$, Valentin I. POPA ${ }^{c}$ \\ ${ }^{a}$ Faculty of Biology, Al. I. Cuza University of Iasi, 20 A Bd. Carol I, 700505 Iasi, Romania \\ ${ }^{b}$ Environmental Engineering and Management Department, Gheorghe Asachi Technical University of Iasi, \\ 71 Bd. Prof. D. Mangeron, 700050 Iasi, Romania \\ 'Institute of Research, Development and Innovation in Technical and Natural Sciences, \\ Aurel Vlaicu University of Arad, 77 Bd Revoluției, 310130 Arad, Romania.
}

Submitted 20 Aug. 2013; accepted 28 Apr. 2014

\begin{abstract}
The current study reveals the results of a phytoremediation process applied to a multi metal contaminated soil, located in close proximity to an energy power plant. Phytoremediation process was studied using the rapeseed cultivation, both in the presence and absence of hemp shives, considered as potential natural soil amendments. The physiological responses of the rapeseed plants, such as variations in length and accumulation of biomass, as well as the content of assimilating pigments were investigated. The concentrations of $\mathrm{Cu}$ (II) and $\mathrm{Pb}$ (II) ions have also been determined in soil and plants aiming at locating the metal ions in different organs of the plants. By using hemp shives as amendments, bioaccumulation of copper and lead ions in plant increases. The plants cultivated in the presence of high amounts of heavy metal ions have been characterized by an inhibition of growth and development that consisted in decrease of root and stem lengths, as well in the amount of biomass accumulated in different vegetative organs.
\end{abstract}

Keywords: heavy metals, soil contamination, phytoremediation, rapeseed, amendments, hemp shives.

\section{Introduction}

The concentrations of heavy metals such as copper and lead in the environment are currently increasing, mainly as a result of industrial activities associated with processes as metal plating and manufacture of batteries, pigments, plastics and fossil fuels burning. Any of these metals, in sufficiently high concentrations, can cause severe damage to physiological and biochemical activities of plants and humans. This damage can be intensified when two or more metals present in soil act synergistically (Jankaite, Vasarevičius 2005).

High concentrations of copper in the growth medium affect the different parameters of plant metabolism including dry biomass production, water content, macro and micro-nutrients balance (Jankaite, Vasarevičius 2005). They also inhibit root growth and block photosynthetic electron transport, thus reducing the content of chlorophyll pigments (Bernal et al. 2007; Kovacik et al. 2006). The inhibition of plant growth in the presence of this metal ion may be the result of degradation of chlorophyll pigments during the photosynthesis process (Upadhyay, Panda 2009).

Humans are exposed to copper via inhalation of particulate copper by occupational exposure or consumption of copper-contaminated water and food. In human body, copper is maintained in homeostasis (Jesse, Mary 2004). If the intake of copper exceeds the limit of human body tolerance, it may lead to toxic effects including hemolysis, jaundice and even death. The overload of common copper in vivo may result in hepatic cirrhosis (Bjorn et al. 2003), changes in lipid profile, oxidative stress, renal dysfunction (Galhardi et al. 2004) and stimulation of mucous membrane of alimentary canal.

Studies on the effects of lead in children have demonstrated a relationship between exposure to lead and a variety of adverse health effects. These effects include impaired mental and physical development, decreased heme biosynthesis, elevated hearing threshold, and decreased serum levels of vitamin D. The neurotoxicity of lead is of particular concern, because evidence from prospective longitudinal studies has shown that neurobehavioral effects, such as impaired academic performance and deficits in motor skills, may persist even after $\mathrm{Pb}$ (II) levels have returned to normal (Needleman 2004).

Corresponding author: Irina Volf

E-mail: iwolf@tuiasi.ro 
In order to ensure the protection of soil, as a mean of increasing soil resources and environmental protection, different methods and technologies of bioremediation were designed to neutralize or block the flow of pollutants and to obtain an efficient and proper protection for a desired quality of soil (Stingu et al. 2010).

Phytoremediation is a cost effective and eco-friendly "green" remediation technology for environmental cleanup. Among the phytoremediation techniques, the phytoextraction consists in removal of trace elements from soil through their uptake and accumulation by plants (Nascimento, Xing 2006). By harvesting the resulted plant biomass that contains heavy metals, these are removed from the site. This technique is effective only if the plants accumulate high concentrations of metals/metalloids in shoots (Stingu et al. 2011) and a reasonable amount of biomass is produced (McGrath, Zhao 2003). Phytoextraction is best suited for the remediation of diffusively polluted areas, where pollutants occur superficially in a relatively low concentration. Phytostabilisation is considered to be a particular phytoremediation technique, which aims at establishing a vegetation cover and causing in situ inactivation of trace elements by combining the use of metaltolerant plants with soil amendments. These result in decrease of mobility and toxicity of pollutants concomitant with increase of soil fertility and improvement of plant establishment. The plants recommended for phytostabilisation should retain the metals at the root level restricting their transport to aerial parts thus avoiding the further transfer into the food chain (Wenzel et al. 1999).

One approach to increase the uptake of heavy metals is the use of chelators to mobilize the metals to the root zone (Madrid et al. 2003). Synthetic chelates have been successfully used to induce accumulation of metals by high biomass plants but they pose serious environmental drawbacks regarding excessive amount of metals solubilized and being poorly biodegraded in the soils (Luo et al. 2006). Increasing interest in the replacement of synthetic chelators has determined to research into natural sources of chelating agents, especially using plants as raw materials (Volf et al. 2012). This will allow a possibility to valorize waste industrial products which represent an important challenge of sustainable development based on environmentally friendly processes correlated with complex processing of biomass. Another approach is the use of soil amendments: material added to a soil to improve its physical properties as water retention, permeability, water infiltration, drainage, aeration and structure, with a view to provide a better environment for roots development (Davis, Wilson 2005). Hemp shives can be used as soil amendments. When the hemp stocks are processed, about $70-80 \%$ of the initial material is rejected as shives, which are not used conveniently evermore; sometimes used as low quality construction materials (tiles that contain fiber, gypsum, cement), as bedding for composting in agriculture, or are converted into fuel briquettes. However, the accessibility of these products led currently to their usage as soil amendment in phytoremediation.

Bioactive compounds existing in aqueous extracts modulated the bioaccumulation process of cadmium ions in Avena sativa depending on heavy metal concentrations and polyphenolic extracts compositions (Stingu et al. 2011). Picea abies bark and Asclepia syriaca plant extracts, both of them containing polyphenolic compounds, stimulated cadmium bioaccumulation, promoting the translocation of heavy metals to the aerial part of the plant. The conclusion of Stingu et al. (2011) study was that polyphenolic extracts could be properly used in bioremediation.

In this context, the current study examined the possibility to enhance copper and lead tolerance/bioaccumulation by adding natural products as hemp shives in soil. The relation between natural products and heavy metal tolerance/bioaccumulation was investigated for Brassica napus L. plant, cultivated on multi-metal polluted soils which were sampled from the neighborhood of an energy power plant.

The possibility of using natural amendments in heavy metals phytoremediation was investigated through all specific methods for plants (biometric measurements and quantitative determination of plant biomass and content of photoassimilating pigments: chlorophyll $a$, chlorophyll $b$ and carotenoids) and soils analysis.

\section{Methodology}

\subsection{Soil samples}

The soil samples (S1, S2, S3) taken at different distances from the energy power plant (using coal as fuel) (Table 1) were characterized in terms of water content, $\mathrm{pH}$ value and content of heavy metal ions as copper, lead, iron, cadmium and zinc. For the content of heavy metal ions analysis, the soil samples were first digested with a mixture of hydrochloric and nitric acids $(10.5 \mathrm{~mL} \mathrm{HCl} 12 \mathrm{~mol} / \mathrm{L}$ and $3.5 \mathrm{~mL} \mathrm{HNO}{ }_{3} 15.8 \mathrm{~mol} / \mathrm{L}$ ) for 12 hours and, subsequently, they were kept on a hot plate for another 2 hours. The concentrations of heavy metal ions were determined using a GBC 2008 Avanta Atomic Absorption Spectrophotometer, Germany (Stingu et al. 2009).

Table 1. Location of soil sampling sites

\begin{tabular}{cc}
\hline $\begin{array}{c}\text { Soil } \\
\text { sample }\end{array}$ & \multicolumn{1}{c}{ Location of soil sampling sites } \\
\hline S1 & $\begin{array}{c}500 \mathrm{~m} \text { E from the slag and ash storage yard and } \\
1.5 \mathrm{~km} \text { from the flue gas stack }\end{array}$ \\
S2 & $\begin{array}{c}700 \mathrm{~m} \text { SE from the slag and ash storage yard and } \\
\end{array}$ \\
S3 & $\begin{array}{l}1.3 \mathrm{~km} \text { from the flue gas stack } \\
\text { 1.8 } \mathrm{km} \text { NE from the slag and ash storage yard and } \\
\end{array}$ \\
\hline
\end{tabular}




\subsection{Characterization of hemp shives}

The hemp shives used in this study are wastes resulted after bast fibers separation. The vegetal material was randomly collected, while the species was identified and authenticated. The vegetal material was shade-dried at room temperature for two weeks, a reference sample (control) being kept for comparison. For chemical characterization, 20 grams of ground dried material with particle size of 0.5-1 $\mathrm{mm}$ were extracted consecutively for three times with $125 \mathrm{~mL}$ distilled water on a water bath, for $45 \mathrm{~min}$ utes, at $80^{\circ} \mathrm{C}$, and finally, the extracts were cumulated to a final volume of $500 \mathrm{~mL}$ using distilled water. Dry matter content in the extracts was determined by evaporation of $25 \mathrm{~mL}$ extract on water bath and drying at $105^{\circ} \mathrm{C}$, until a constant mass is reached. After that the crucible containing the dry matter was placed into a furnace at $600{ }^{\circ} \mathrm{C}$, in order to establish the mineral and organic matter content. Folin Ciocalteu (FC) method was used to determine the total polyphenolic content (TPC) in aqueous extract and the concentrations were expressed as the number of equivalents of gallic acid (GAE) (Bao et al. 2005; Ignat et al. 2011). For the HPLC analysis, the cumulated aqueous extracts were concentrated under vacuum to $10 \mathrm{~mL}$. Before HPLC characterization the concentrated sample was subjected to a fractionation step by successive liquidliquid extractions with ethyl acetate. The organic phases were evaporated to dryness, diluted in methanol and further subjected to HPLC analysis.

A reversed-phase high-performance liquid chromatographic technique was used to identify and quantify the phenolic compounds. The HPLC analysis was carried out using a Dionex UltiMate 3000 chromatograph LC Systems, Germany, coupled to a PDA detector. Separations were performed with a Zorbax RX C18 $(4.6 \times 250 \mathrm{~mm}$, particle size $5 \mu \mathrm{m}$ ) column, operating at $30^{\circ} \mathrm{C}$ with a flow rate of $1.2 \mathrm{~mL} / \mathrm{min}$, and the injection volume was $5 \mu \mathrm{L}$. The mobile phase used was $1 \%$ acetic acid in water (A) versus methanol (B) for a total run time of $40 \mathrm{~min}$, and the gradient changed as follows: solvent B started at $10 \%$ and increased immediately to $40 \%$ in $40 \mathrm{~min}$. For quantification, standards for external calibration were used.

\subsection{Experimental assay}

Three different samples of contaminated soils were tested in different conditions, both in the absence (S1, S2, S3) and presence (S11, S22, S33) of hemp shives $\left(1 \mathrm{~g} / 30 \mathrm{~cm}^{2}\right)$. The plants have been cultivated in greenhouse conditions using those three samples of contaminated soils (100 g/pot). Brassica napus L. seeds were directly sown into pots. Each sample was replicated in ten pots, and three uniform plants have been spaced evenly in each pot and were allowed to grow.

The cultivated soils were wetted daily with $15 \mathrm{~mL}$ tap water for one week, until germination of the plants was observed. From this point, rapeseed plants were wetted every two days with the same amount of water. After 45 days from the beginning of the experiments, the rapeseed plants were separated into roots, coleoptiles and leaves which were characterized in order to evidence the different effects of the cultivation conditions on plants growth and development (Fig. 1).

\subsection{Plantlet analysis}

Plant growth and development. To evaluate the influence of natural amendment on plant growth and development in multi-metal stress conditions, after ten days, the rapeseed plants were separated into roots, stems and primary leaves, followed by biometric measurements of plant elongation and quantitative determinations of biomass. Samples of separated plant have been oven dried at $70{ }^{\circ} \mathrm{C}$ until constant values of mass were reached and the dry biomass was quantified.

Determination of heavy metal concentration in plants. For heavy metals ions analysis, plant tissues (root, stem and leaves) were digested with a mixture of nitric and

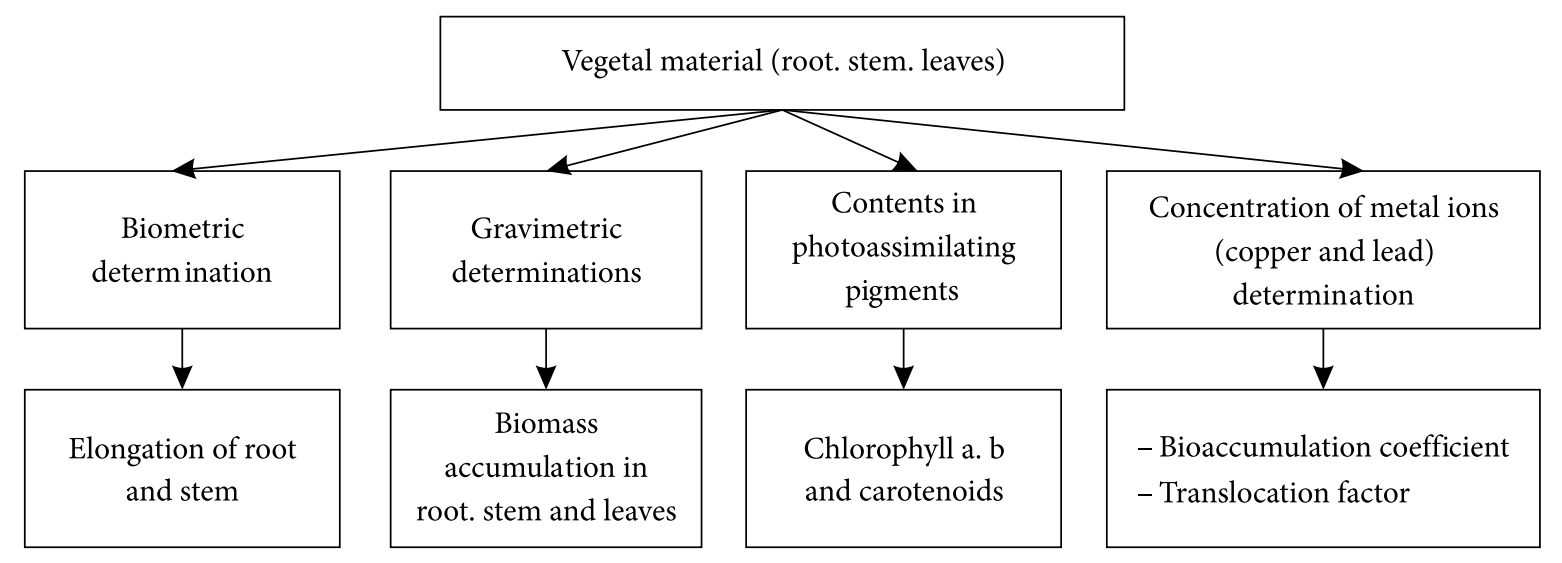

Fig. 1. Research methodology on plant material (Brassica napus L.) 
hydrochloric acids similar to the case of soil samples. The concentrations of copper were determined by calibration curves obtained using standard solutions of pure copper and lead ions (Fisher Scientific). Calibration curves were generated using three replicates per metal concentration $(0.02-5.00 \mu \mathrm{g} / \mathrm{mL})$ by reading the absorbance at fixed wavelength.

The following parameters have been calculated:

Translocation factor $(\mathrm{TF})=$ metal concentration in shoots $(\mathrm{mg} / \mathrm{kg}) /$ metal concentration in roots $(\mathrm{mg} / \mathrm{kg})$ (Sun et al. 2009).

Bioaccumulation coefficient $=($ metal concentration $\mathrm{mg} / \mathrm{kg}$ dry plant tissue) / (metal concentration $\mathrm{mg} / \mathrm{kg}$ soil samples) (Stingu et al. 2009).

Photoassimilating pigments assay. The chlorophyll was extracted in $80 \%$ acetone and determined spectrophotometrically by measuring the absorbance at fixed wavelengths of $470\left(\mathrm{~A}_{470}\right), 646\left(\mathrm{~A}_{646}\right)$ and $663 \mathrm{~nm}$ $\left(\mathrm{A}_{663}\right)$.

The concentrations of chlorophyll pigments (chlorophyll $a$ and $b$ : [chl a] and [chl b]) were calculated by using the specific coefficients (Lichtenthaler, Wellburn 1983).

Chlorophyll $a(\mu \mathrm{g} / \mathrm{mL})=12.21 \times \mathrm{A}_{663}-2.81 \times \mathrm{A}_{646}$;

Chlorophyll $b(\mu \mathrm{g} / \mathrm{mL})=20.13 \times \mathrm{A}_{646}-5.03 \times \mathrm{A}_{663}$;

Carotenoids $(\mu \mathrm{g} / \mathrm{mL})=\left(100 \mathrm{~A}_{470}-3.27[\mathrm{chl} \mathrm{a}]-104[\mathrm{chl} \mathrm{b}]\right) /$ 227.

Statistical analysis. All the results are expressed as mean \pm standard error where $n=3$. Comparison of the means was performed by the Fisher least significant

Table 2. Characterization of the soil samples

\begin{tabular}{cccccccc}
\hline Sample & $\begin{array}{c}\text { Water } \\
\text { content } \\
(\%)\end{array}$ & pH value & $\begin{array}{c}\text { Lead ions } \\
\text { concentration } \\
(\mathrm{mg} / \mathrm{kg})\end{array}$ & $\begin{array}{c}\text { Copper ions } \\
\text { concentration } \\
(\mathrm{mg} / \mathrm{kg})\end{array}$ & $\begin{array}{c}\text { Iron ions } \\
\text { concentration } \\
(\mathrm{mg} / \mathrm{kg})\end{array}$ & $\begin{array}{c}\text { Cadmium ions } \\
\text { concentration } \\
(\mathrm{mg} / \mathrm{kg})\end{array}$ & $\begin{array}{c}\text { Zinc ions } \\
\text { concentration } \\
(\mathrm{mg} / \mathrm{kg})\end{array}$ \\
\hline $\mathrm{S} 1$ & $19 \pm 1.03^{\mathrm{b}}$ & $7.53 \pm 0.14^{\mathrm{b}}$ & $549 \pm 13.67^{\mathrm{a}}$ & $330 \pm 9.93^{\mathrm{b}}$ & $36216 \pm 24.32^{\mathrm{c}}$ & $0.11 \pm 0.00^{\mathrm{a}}$ & $74 \pm 1.43^{\mathrm{a}}$ \\
$\mathrm{S} 2$ & $15 \pm 0.89^{\mathrm{b}}$ & $7.43 \pm 0.12^{\mathrm{b}}$ & $301 \pm 8.86^{\mathrm{c}}$ & $464 \pm 11.42^{\mathrm{a}}$ & $51268 \pm 43.21^{\mathrm{a}}$ & $0.09 \pm 0.00^{\mathrm{b}}$ & $65 \pm 0.92^{\mathrm{b}}$ \\
$\mathrm{S} 3$ & $25 \pm 1.23^{\mathrm{a}}$ & $7.72 \pm 0.21^{\mathrm{a}}$ & $242 \pm 5.49^{\mathrm{d}}$ & $344 \pm 10.78^{\mathrm{b}}$ & $24175 \pm 21.33^{\mathrm{d}}$ & $0.08 \pm 0.00^{\mathrm{b}}$ & $55 \pm 0.59^{\mathrm{c}}$ \\
\hline
\end{tabular}

Different letters within columns indicate significant differences $(\mathrm{p}<0.05)$.

Table 3. Characteristics of hemp shives aqueous extract

\begin{tabular}{cccccccc}
\hline $\begin{array}{c}\text { Dry mater } \\
\text { content } \\
(\mathrm{g} / \mathrm{L} \text { extract })\end{array}$ & $\begin{array}{c}\text { Organic } \\
\text { matter content } \\
(\mathrm{g} / \mathrm{L} \text { extract })\end{array}$ & $\begin{array}{c}\mathrm{pH} \\
\left(\text { at } 25^{\circ} \mathrm{C}\right)\end{array}$ & $\begin{array}{c}\mathrm{TPC} \\
(\mathrm{g} / 100 \mathrm{~g})\end{array}$ & $\begin{array}{c}\text { Catechins } \\
(\mathrm{g} / 100 \mathrm{~g})\end{array}$ & $\begin{array}{c}\text { Caffeic acid } \\
(\mathrm{g} / 100 \mathrm{~g})\end{array}$ & $\begin{array}{c}\mathrm{p}-\text { coumaric } \\
\text { acid } \\
(\mathrm{g} / 100 \mathrm{~g})\end{array}$ & $\begin{array}{c}\text { Ferulic acid } \\
(\mathrm{g} / 100 \mathrm{~g})\end{array}$ \\
\hline $0.51 \pm 0.003$ & $0.42 \pm 0.003$ & $4.7 \pm 0.2$ & $16.41 \pm 0.62$ & $5.21 \pm 0.23$ & $9.68 \pm 0.35$ & $0.80632 \pm 0.02$ & $0.32598 \pm 0.005$ \\
\hline
\end{tabular}

Results reported represent the average values of triplicate determinations $(n=3) \pm$ standard error. TPC - total polyphenolic content.

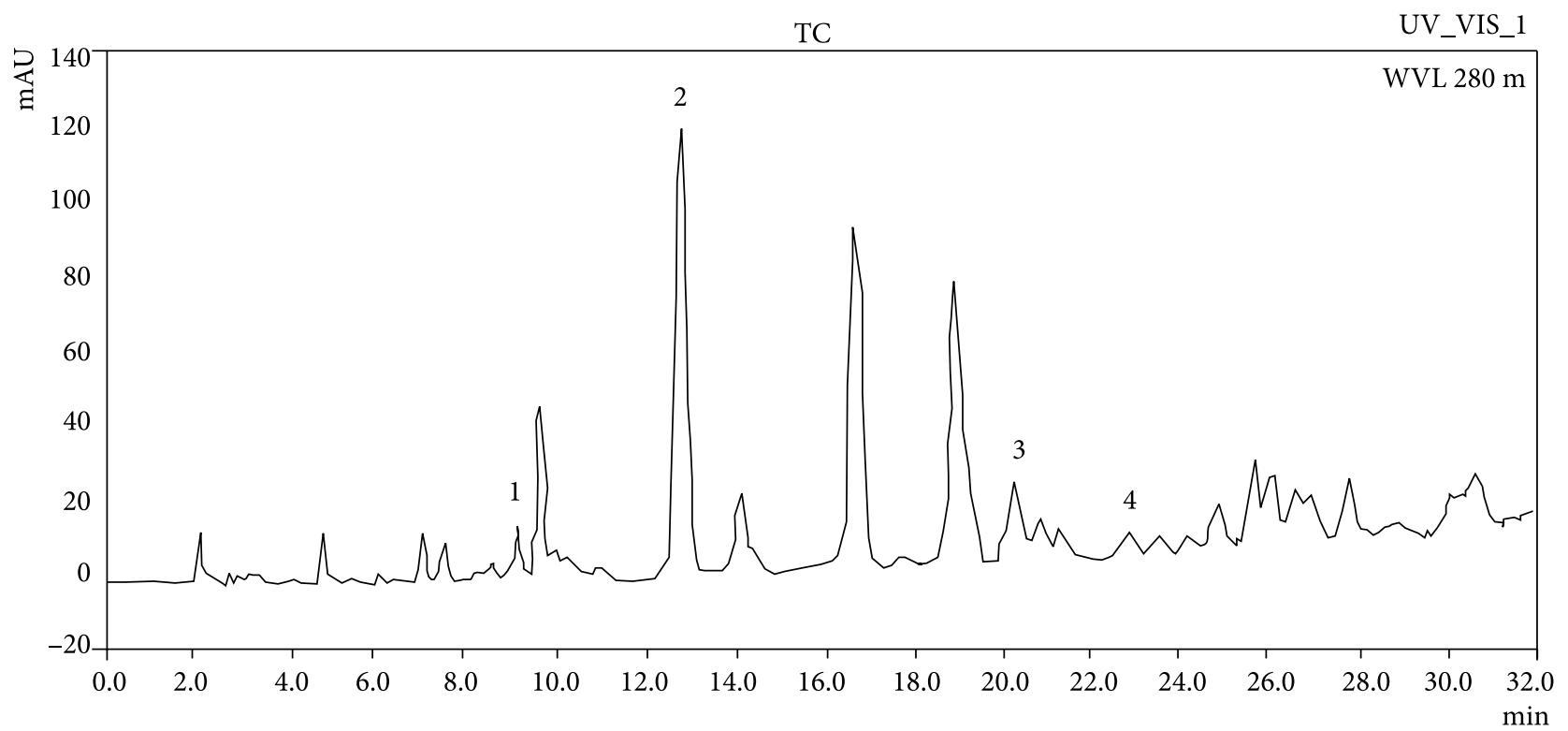

Fig. 2. Chromatographic profile of hemp shives aqueous extract: 1: catechin; 2 - caffeic acid; 3 - p-coumaric acid; 4 - ferulic acid 
difference (LSD) test $(\mathrm{p} \leq 0.05)$ after ANOVA analysis using program PAST 2.14. Sampling and chemical analyses were examined in triplicate, in order to decrease the experimental errors and to increase the experimental reproducibility.

\section{Results and discussion}

\subsection{Characterization of the soil samples}

The characterisation of soil samples showed a multi-metal polluted soil. As concerns the water content (Table 2), the highest value is recorded in sample S3. The specific humidity of S3 soil sample, taken at $1.8 \mathrm{~km}$ NE from the slag and ash storage yard and $300 \mathrm{~m}$ from the flue gas stack exhibits a slight increase compared to other areas as a result of the fact that this soil belongs to swampy areas.

The $\mathrm{pH}$ of the three sampling sites is slightly alkaline. The $\mathrm{pH}$ value has a direct influence on the mobility and accessibility of nutrients into soil. Optimal $\mathrm{pH}$ domain for plant nutrition is ranged between 6.0 and 6.5, since between these values the solubility and optimum accessibility of most nutrients at soil level are ensured. In general, for a normal development, the plants need a soil with $\mathrm{pH}$ values ranged between 6.5 and 7.2. Alkaline soil reaction is unfavorable for most crops and causes a low fertility of soils (Wang et al. 2004).

The concentrations of the studied heavy metals ions (Pb (II), Cu (II)) in the three soils samples tested (S1, S2, S3), have exceeded the alert threshold laid down in regulations (MWFEP 1997), excepting the value of lead ions in S3, which is very close to the limit of alert allowed. The highest concentration of lead ions was found in the soil sample S1, located at the nearest distance from slag and ash storage yard and $1.5 \mathrm{~km}$ from the flue gas stack. The content of lead ions has decreased as the distance to storage yard has increased. $\mathrm{Pb}$ (II) and $\mathrm{Cu}$ (II) were chosen for the trials due to high risk and transferability, though other heavy metal ions (iron, cadmium, zinc) were also determined in soil samples.

High concentration of potentially mobile $\mathrm{Pb}(\mathrm{II})$ and $\mathrm{Cu}(\mathrm{II})$ in soil run the risk of their downward migration and possible contamination of groundwater.

\subsection{Characterization of the hemp shives extract}

The total polyphenols content of hemp shives aqueous extract was $16.41 \pm 0.62 \mathrm{~g} / 100 \mathrm{~g}$. The chromatographic analysis has allowed identification and quantification of components as catechin and phenolic acids, (Fig. 2 and Table 3), along with other compounds. Thus, the amount of catechins was $5.21 \mathrm{~g} / 100 \mathrm{~g}$ plant material; caffeic acid was presented in a higher concentration (9.68 g/100g) compared with those of other identified phenolic acids.

\subsection{Rapeseed plantlet growth and development}

The rape was chosen because it is considered as a plant with a high potential to be used for polluted soil remediation. The sorption of metals from the soil by plants is influenced by a variety of factors, including $\mathrm{pH}$, temperature, soil ions, the cation exchange capacity of the soil, organic matter content of the soil, the type and concentration of metal, and the species of plant. The metals enter the root in the form of dissolved ions and move with the inflow of water apoplastically through the root hairs and into the cortex and are then translocated to other parts of plants. The metals interact with the physiological and biochemical activities of plants to reduce their vigour and in extreme cases can completely inhibit growth.

Lead has been shown to have toxic effects on a variety of metabolic processes essential to plant growth and development, including photosynthesis, transpiration, DNA synthesis, and mitotic activity. Of these processes, photosynthesis was found to be the most sensitive to lead contamination. Lead occurs in soils in the form of insoluble minerals and soluble compounds. It tightly binds to organic soil particles which may decrease the mobility of lead in most soils and may reduce uptake by plants.

Copper, unlike lead, is necessary for the growth of plants. It functions as a structural and catalytic component of several enzymes and proteins. Despite this requirement, excess copper when absorbed by plants can be toxic, leading to reduced growth, chlorosis, and malformation of roots.

The stem and root elongation of rapeseed plants (Fig. 3) which have been cultivated in the presence of amendments (S11, S22, S33) is usually significantly lower compared to the variants without amendments (S1, S2, S3). A special situation is recorded for root of rapeseed plants cultivated in S33 variant, where the elongation is significantly higher than the control (S3). Biomass accumulated in vegetative organs is presumed to be directly proportional to their length increase.

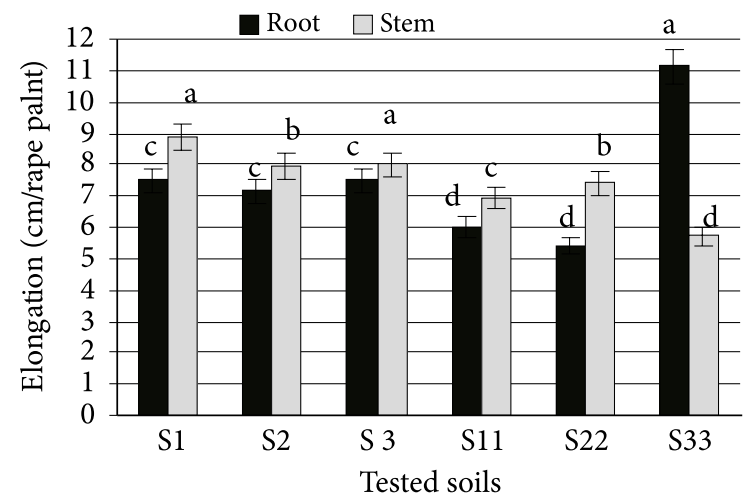

Fig. 3. Elongation of vegetative organs of rapeseed plants. Bars showing the same letter are not significantly different at $\mathrm{p} \leq 0.05$. Error bars represent the standard error of means $(n=3)$ 
An inhibition in accumulation of the dry biomass in stems and leaves was obvious in experimental variants containing hemp shives as amendment, but in roots the opposite tendency prevailed, especially in S33 (Fig. 4 and Fig. 5). The results could be correlated with the characteristics features of soils samples. The sample S3 from swampy area possibly contains more and different microorganisms which can be involved in the interactions with

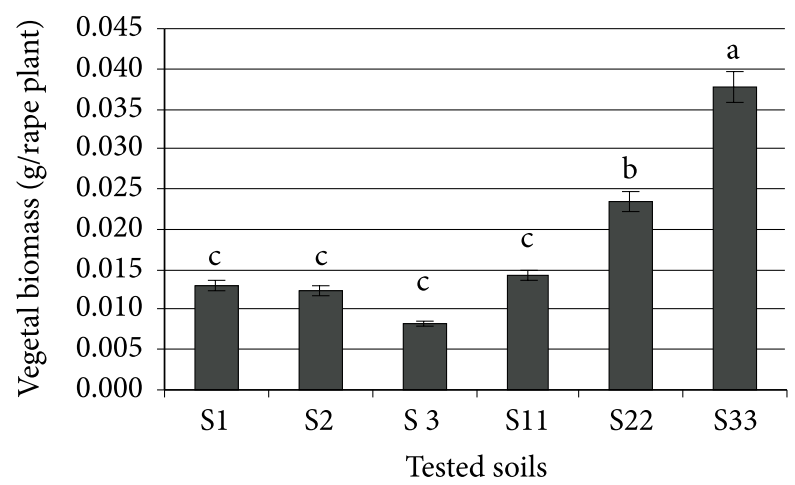

Fig. 4. Accumulation of biomass in roots of rapeseed plants under multi-metal stress conditions. Bars showing the same letter are not significantly different at $\mathrm{p} \leq 0.05$. Error bars represent the standard error of means $(n=3)$

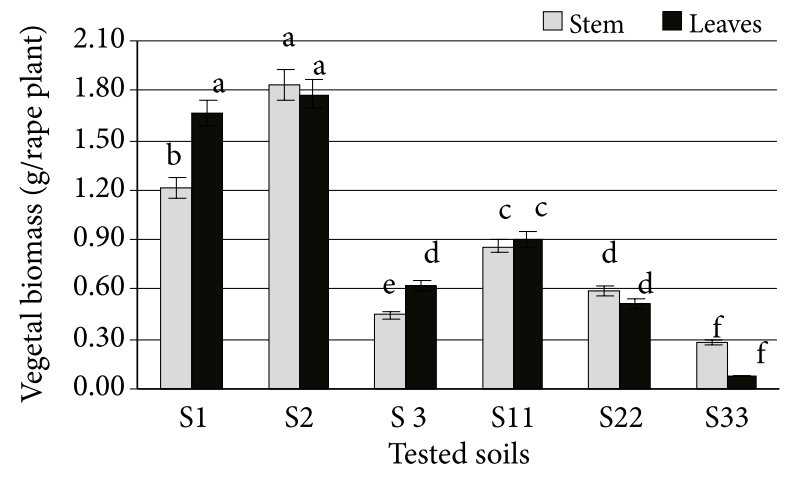

Fig. 5. Accumulation of biomass in stem and leaves of rapeseed plants under multi-metal stress conditions. Bars showing the same letter are not significantly different at $\mathrm{p} \leq 0.05$. Error bars represent the standard error of means $(n=3)$

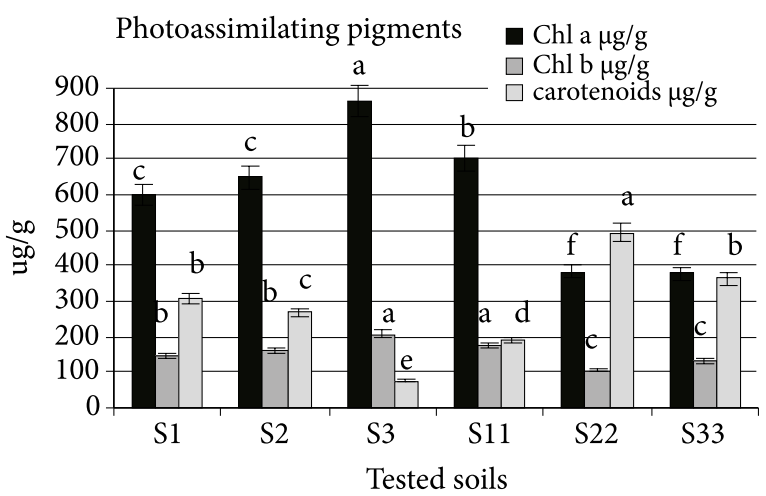

Fig. 6. Content of photo assimilating pigments in rapeseed leaves. Bars showing the same letter are not significantly different at $\mathrm{p} \leq 0.05$. Error bars represent the standard error of means $(n=3)$ the other components of the system (e.g. pollutants, polyphenols, products resulting in biomass transformation).

\subsection{Photoassimilating pigments}

The photosynthetic apparatus may be especially sensitive to damage in the presence of heavy metals. An excess of heavy metals could negatively affect photoassimilating pigments biosynthesis.

Analyzing the variation of content of assimilating pigments (Fig. 6), a difference between the experimental variants was observed, that seems to be influenced by peculiarities of rapeseed plants and characteristic features of the soil samples. Thus the quantity of chlorophyll $a$ (Chl a) in S11 variant has significantly higher value than those recorded in the case of the plants that have been developed in the absence of hemp shives. On the contrary, for S22 and S33 variants, the values are significantly lower than those recorded in case of the plants that have been developed in the absence of hemp shives.

The same trend is recorded for chlorophyll $b(\mathrm{Chl} \mathrm{b})$. So in most cases the leaves of rapeseed plants were significantly affected by copper and lead ions, which resulted in a decline of chlorophyll content. Copper and lead ions inhibit chlorophyll biosynthesis and retard the incorporation of these pigments in photosynthesis. Concerning the accumulation of carotenoids, the situation is opposite (Fig. 6). Significantly higher amounts of carotenoids were observed in S22 and S33 variants compared to values recorded for the plants cultivated in the variants S2 and S3. The leaves of rapeseed plants were significantly affected by copper and lead ions, which resulted in a decline of chlorophyll content. Copper and lead ions inhibit chlorophyll and carotene biosynthesis, and retard the incorporation of these pigments in photosynthesis.

From these results it seems that at the level of the soil, in the presence of humidity an extraction of polyphenols from hemp shives is possible. At the same time, an interaction of polyphenols with soil microorganisms and heavy metals could influence the plants development and their metabolism. It is known that polyphenols are also involved in metal complexing, plant growth regulation (oxidative phosphorylation) and reactive oxygen species inhibition. When a plant is exposed to more than one pollutant, interactions between those pollutants may occur. Although heavy metals may have antagonistic, additive, or synergistic effects in plants, synergistic interactions are found to be most common. The presence of hemp shives and its decomposition products could also influence this complex process.

\subsection{Heavy metal ions content in plants}

The concentrations of copper ions accumulated in all vegetative organs of rapeseed plants have shown that the 
presence of hemp shives in soil often determines an improvement in the process of bioaccumulation of metal ions (Fig. 7). The presence of natural amendments (hemp shives) in a multi-metal polluted soil has often induced the stimulation of the $\mathrm{Cu}(\mathrm{II})$ bioaccumulation process in plant. The $\mathrm{Pb}$ (II) content accumulated in different parts of rapeseed plants has revealed a similar conclusion (Fig. 8). The presence of hemp shives as amendment in soil usually increases the capacity of bioaccumulation both for copper and lead ions. The accumulation of metals in various parts of plants is often accompanied by an induction of variety of cellular changes, some of which directly contribute to metal tolerance capacity of plants. The high concentration of $\mathrm{Cu}(\mathrm{II})$ in soil (S2) probably caused a significant decrease of bioaccumulation of this element in in the plant leaves. Rapeseed has obviously higher bioaccumulation capacity of $\mathrm{Pb}(\mathrm{II})$ compared with $\mathrm{Cu}(\mathrm{II})$.

In cases of higher metal ion concentration, a decrease in plant growth and development processes were also observed, expressed by significant decrease of biomass accumulated in stems and leaves and usually significant decrease in root and stem lengths. The translocation factor reveals that the presence of hemp shives in heavy metals contaminated soil causes a decrease (usually significant) of metal ions transport to the upper parts of plants for S11 and S22 variants, but a significant increase of their transport for variant S33 (Fig. 9).

These phenomena could be explained by complex interaction between heavy metals, compounds liberated from hemp shives by aqueous elution or action of microorganisms and plants. These mechanisms will be elucidated in our further studies.

\section{Conclusions}

A multi-metal contaminated soil from a site located close to an energy power plant was used to study a bioremediation process using rape seed plants, in both the absence and presence of hemp shives as natural amendments. The development of rapeseed plants cultivated is influenced by the presence of heavy metals ions and hemp shives and the following effects were observed:

1. Prevalence of an inhibitory effect on biomass accumulation in plants demonstrated by significant decrease in lengths of stems and in the amount of biomass accumulated in the stems and leaves.

2. Prevalence of significant decrease in chlorophyll $a$ and $b$ contents and significant increase of carotenoids compared to the values recorded for plants that have grown in the absence of hemp shives.

3. Modulation effects of hemp shives on $\mathrm{Cu}$ (II) and $\mathrm{Pb}$ (II) bioaccumulation in rapeseed plant; the translocation factor calculated indicated a decreased transport of metal ions to the upper parts of plants for S11 and S22

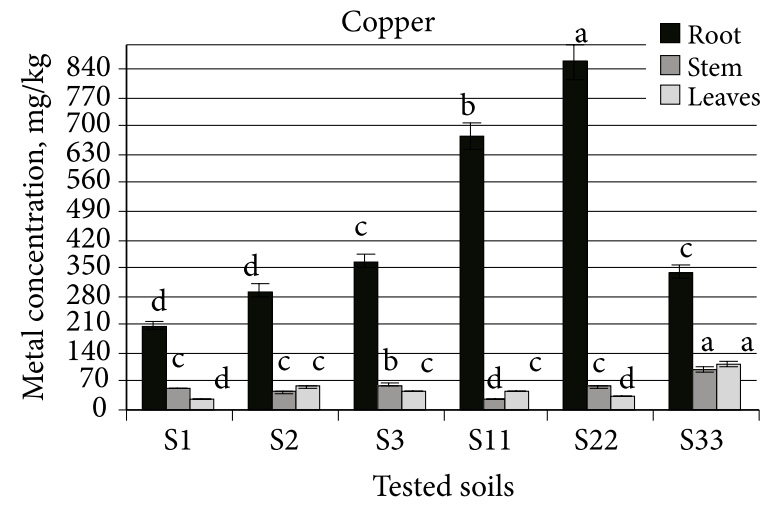

Fig. 7. Bioaccumulation coefficient of $\mathrm{Cu}$ (II) in vegetative organs of rapeseed plants. Bars showing the same letter are not significantly different at $\mathrm{p} \leq 0.05$. Error bars represent the standard error of means $(n=3)$

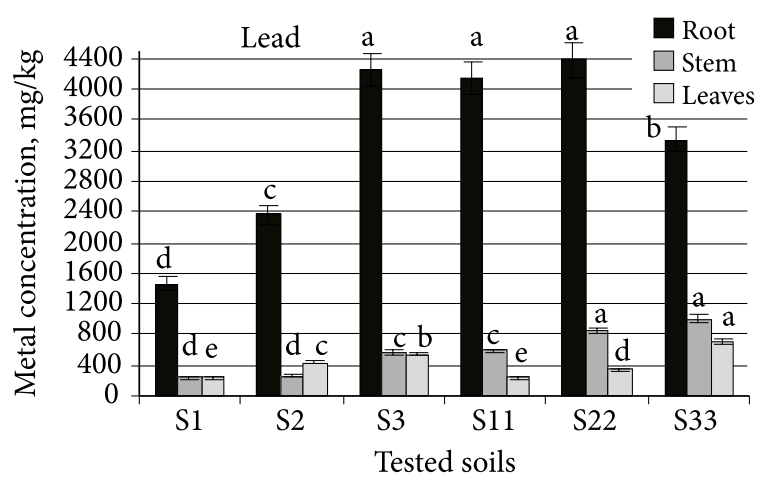

Fig. 8. Bioaccumulation coefficient of $\mathrm{Pb}$ (II) in vegetative organs of rapeseed plants. Bars showing the same letter are not significantly different at $\mathrm{p} \leq 0.05$. Error bars represent the standard error of means $(n=3)$

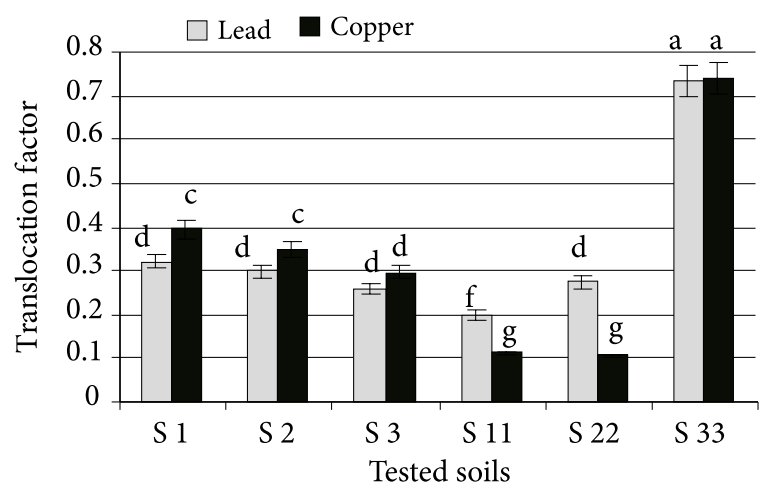

Fig. 9. Translocation factor of rapeseed plants. Bars showing the same letter are not significantly different at $\mathrm{p} \leq 0.05$. Error bars represent the standard error of means $(n=3)$

variants and a promotion of heavy metals to the aerial parts of plant for S33 variant.

4. Bioactive compounds existing in hemp shives aqueous extracts can modulate the bioaccumulation process of lead and copper ions in Brassica napus, depending on heavy metal concentrations in soil. At low concentrations in soil the presence of hemp shives stimula- 
tes lead and copper bioaccumulation, promoting the translocation of heavy metals to the aerial part of the plant. In this case the polyphenolic compounds eluted from hemp shives as natural amendments, increase the solubilisation of heavy metals and improve the phytoextraction process. At higher concentration in soil another effect may take place: reducing $\mathrm{Pb}(\mathrm{II})$ and $\mathrm{Cu}$ (II) mobility, decreasing thus translocation and determining in situ inactivation of heavy metal ions being suitable in phytostabilisation. Presumably, other components of lignocellulose are involved in this process.

5. The prevalence of significant increase of $\mathrm{Pb}$ (II) and $\mathrm{Cu}$ (II) bioaccumulation in different vegetative organs of rapeseed plants after adding hemp shives indicates that they can be recommended to be used as amendments in bioremediation of polluted soils. The results obtained in this study will be further developed with the aim to elucidate the mechanism of the complex interactions of components of the system.

\section{Acknowledgements}

This paper was realized with the support of Project POSCCE - "Bast fibers plants - strategic renewable resources for European economy" - BASTEURES and CUANTUMDOC "Doctoral studies for European performances in research and innovation" projects funded by the European Social Found and Romanian Government.

\section{References}

Bao, J. S.; Cai, Y.; Sun, M.; Wang, G. Y.; Corke, H. 2005. Anthocyanins, flavonols, and free radical scavenging activity of Chinese bayberry (Myrica rubra) extracts and their color properties and stability, Journal of Agricultural and Food Chemistry 53: 2327-2332.

http://dx.doi.org/10.1021/jf048312z

Bernal, A. J.; Jensen, J. K.; Harholt, J.; Sørensen, S.; Moller, I.; Blaukopf, C.; Johansen, B.; de Lotto R.; Pauly, M.; Schelle, H. V. 2007. Disruption of ATCSLD5 results in reduced growth reduced xylan and homogalacturonan synthase activity and altered xylan occurrence in Arabidopsis, Plant Journal 52: 791-802. http://dx.doi.org/10.1111/j.1365-313X.2007.03281.x

Bjorn, P. Z.; Hermann, H. D.; Max, L.; Heide, S.; Barabara, K. G.; Hartmut, D. 2003. Epidemiological investigation on chronic copper toxicity to children exposed via the public drinking water supply, Science of Total Environment 302: 127-144. http://dx.doi.org/10.1016/S0048-9697(02)00399-6

Davis, J. G.; Wilson, C. R. 2005. Choosing a soil amendment, fact sheet, Gardening Series Basics [online], [cited August 2013], Colorado State University No. 7235. Available from Internet: http://www.ext.colostate.edu/pubs/garden/07235.html

Galhardi, C. M.; Diniz, Y. S.; Faine, L. A.; Rodrigues, H. G.; Burneiko, R. C.; Ribas, B. O.; Novelli, E. L. 2004. Toxicity of copper intake: lipid profile, oxidative stress and susceptibility to renal dysfunction, Food Chemistry and Toxicology 42: 2053-2060.

http://dx.doi.org/10.1016/j.fct.2004.07.020
Ignat, I.; Volf, I.; Popa, V. I. 2011. A critical review of methods for characterization of polyphenolic compounds in fruits and vegetables, Food Chemistry 126: 1821-1835. http://dx.doi.org/10.1016/j.foodchem.2010.12.026

Jankaite, A.; Vasarevičius, S. 2005. Remediation technologies for soils contaminated with heavy metals, Journal of Environmental Engineering and Landscape Management 13(2): 109-113. http://dx.doi.org/10.1080/16486897.2005.9636854

Jesse, B.; Mary, R. L. 2004. Maintaining copper homeostasis regulation of copper-trafficking proteins in response to copper deficiency or overload, Journal of Nutritional Biochemistry 15: 316-322. http://dx.doi.org/10.1016/j.jnutbio.2004.02.004

Kovacik, J.; Tomko, J.; Backor, M.; Repcak, M. 2006. Matricaria chamomilla is not a hyperaccumulator, but tolerant to cadmium stress, Journal of Plant Growth Regulation 50: 239-247. http://dx.doi.org/10.1007/s10725-006-9141-3

Lichtenthaler, H. K.; Wellburn, A. R. 1983. Determinations of total carotenoids and chlorophylls a and b of leaf extracts in different solvents, Biochemical Society Transactions 11: 591-593.

Luo, C.; Shen, Z.; Lou, L.; Li, X. 2006. EDDS and EDTA enhanced phytoextraction of metals from artificially contaminated soils and residual effects of chelant compounds, Environmental Pollution 144: 862-871.

http://dx.doi.org/10.1016/j.envpol.2006.02.012

Madrid, F.; Liphadzi, M. S.; Kirkham, M. B. 2003. Heavy metal displacement in chelate-irrigated soil during phytoremediation, Journal of Hydrology 271: 107-119. http://dx.doi.org/10.1016/S0022-1694(02)00258-5

McGrath, S. P.; Zhao, F. J. 2003. Phytoremediation of metals and metalloids from contaminated soils, Current Opinion in Biotechnology 14: 277-282. http://dx.doi.org/10.1016/S0958-1669(03)00060-0

MWFEP. 1997. Ministry of Waters, Forests and Environment Protection, Order No. 184 - September 21st, 1997 on the approval of the procedure for the carrying out of environmental balance sheets (Annex 4).

Nascimento, C. W. A.; Xing, B. 2006. Phytoextraction: a review on enhanced metal availability and plant accumulation, Sciencia Agricola 63: 299-311.

http://dx.doi.org/10.1590/S0103-90162006000300014

Needleman, H. 2004. Lead poisoning, Annual Review Medicine 55: 209-22.

http://dx.doi.org/10.1146/annurev.med.55.091902.103653

Stingu, A.; Volf, I.; Popa, V. I. 2009. Study of copper and cadmium accumulation by bean, Environmental Engineering and Management Journal 5: 1247-1252.

Stingu, A.; Volf, I.; Popa, I. V. 2010. Spruce bark extract as modulator in rape plant copper bioaccumulation, Cellulose Chemistry and Technology 45: 281-286.

Stingu, A.; Volf, I.; Popa, V. I.; Gostin, I. 2011. New approaches concerning the utilization of natural amendments in cadmium phytoremediation, Industrial Crops and Products 35: 53-60. http://dx.doi.org/10.1016/j.indcrop.2011.06.005

Sun, Y.; Zhou, Q.; Liu, W.; An, J.; Xu, Z.; Wang, L. 2009. Joint effects of arsenic and cadmium on plant growth and metal bioaccumulation: a potential Cd hyperaccumulator and Asexcluder Bidens pilosa L, Journal of Hazardous Materials 161: 808-814. http://dx.doi.org/10.1016/j.jhazmat.2008.04.030

Upadhyay, R. K.; Panda, S. K. 2009. Copper induced growth inhibition, oxidative stress and ultrastructural alterations in 
freshly grown water lettuce (Pistia stratiotes L.), Comptes Rendus Biologies 332: 623-632.

http://dx.doi. org/10.1016/j.crvi.2009.03.001

Volf, I.; Stingu, A.; Popa, V. I. 2012. New natural chelating agents with modulator effects on copper phytoextraction, Environmental Engineering and Management Journal 11: 487-491 [online], [cited August 2013]. Available from Internet: http:// omicron.ch.tuiasi.ro/EEMJ/isues/vol11/vol11no2.htm

Wang, C.; Isoda, A.; Wang, P. 2004. Growth and yield performance of some cotton cultivars in Xinjiang China, an arid area with short growing period, Journal of Agronomy and Crop Science 190: 177-183.

http://dx.doi.org/10.1111/j.1439-037X.2004.00090.x

Wenzel, W. W.; Lombi, E.; Adriano, D. 1999. Biogeochemical processes in the rhizosphere: role in phytoremediation of metal-polluted soils, in N. Prasad; J. Hagemeyer (Eds.). Heavy metal stress in plants - from molecules to ecosystems. Heidelberg: Springer Verlag, 273-303. http://dx.doi.org/10.1007/978-3-662-07745-0_13

Corneliu TANASE. Doctor of Science (Biology and Chemical Engineering), “Al. I. Cuza” University of Iasi (Romania) 2012. Author of 1 book, author of 7 peer-reviewed journal articles indexed in International Data Bases, 12 international conference proceeding publications. Phd, Gheorghe Asachi Technical University of Iasi. Research interests: plant physiology, bioremediation of degraded land and poor crop production based on vegetal material, regulators of plant growth based on natural products.

Irina VOLF. Associate Professor, Gheorghe Asachi Technical University of Iasi, Environmental Engineering and Management Department, Senior Researcher. Doctor of Science (Chemical Engineering), Gheorghe Asachi Technical University of Iasi (Romania), 2002. Publications: author of 6 books, author/co-author of 5 book chapters, 40 ISI peer-reviewed journal articles, 35 peer-reviewed journal articles indexed in international databases, 35 international conference proceeding publications, 1 patent. Internal and international scientific projects: 24 . Research interests: biomass conversion, natural treatment systems: bioremediation of degraded land and poor crop production based on vegetal material (peat, sawdust, lignocellulose and polyphenolic products) as amendments, phytoremediation, regulators of plant growth based on natural products, industrial biotechnology.

Valentin I. POPA. Professor of Wood chemistry and Biotechnology. Publications: books and chapters of book 43, 600 papers, 6 patents. Editor of books in the fields of polysaccharides and polymeric biomaterials (Smithers Rapra and CRC Pess). Supervisor of PhD program-thesis defended: 30. Internal and international scientific projects: 60. Research interest: chemical and structural composition of biomass (cellulose, hemicelluloses, lignin secondary compounds), biorefining, biological properties of natural compounds with aromatic structure, biosynthesis and biodegradation of chemical compounds of biomass, bioremediation. Editor in chief of Cellulose Chemistry and Technology journal. 